\title{
Temperature changes derived from phenological and natural evidence in South Central China from 1850 to 2008
}

\author{
J. Zheng ${ }^{1}$, Z. Hua ${ }^{1,2}$, Y. Liu ${ }^{1,2}$, and Z. Hao ${ }^{1}$ \\ ${ }^{1}$ Key Laboratory of Land Surface Pattern and Simulation, Institute of Geographic Sciences and Natural Resources Research, \\ Chinese Academy of Sciences, Beijing 100101, China \\ ${ }^{2}$ College of Resources and Environment, University of Chinese Academy of Sciences, Beijing 100049, China
}

Correspondence to: Z. Hao (haozx@igsnrr.ac.cn)

Received: 31 July 2015 - Published in Clim. Past Discuss.: 31 August 2015

Revised: 6 November 2015 - Accepted: 11 November 2015 - Published: 20 November 2015

\begin{abstract}
Annual temperature anomalies in South Central China from 1850 to 2008 are reconstructed by synthesizing three types of proxies: spring phenodates of plants recorded in historical personal diaries and observations, snowfall days extracted from historical archives and observed at meteorological stations, and five tree-ring width chronologies. Instrumental observation data and the leave-one-out method are used for calibration and validation. The results show that the temperature series in South Central China exhibits interannual and decadal fluctuations since 1850. The first three cold decades were the 1860s, 1890s, and 1950s, while 1893 was very likely the coldest year. Except for the three warm decades that occurred around 1850, 1870, and 1960, along with the 1920s to the 1940s, the recent warm decades of the 1990s and 2000s represent unprecedented warming since 1850 .
\end{abstract}

\section{Introduction}

Long-term temperature data have been essential for assessing global warming and regional climate change over the last century (Jones et al., 1999). Significant progress has been made in the use of homogeneous surface air temperature (SAT) data sets to make average hemispheric and global estimates, and several SAT data sets have been compiled (Hansen et al., 2010; Lawrimore et al., 2011; Jones et al., 2012; Rohde et al., 2013); the data set with the greatest temporal coverage extends back to the 1850 s. Although some sparse instrumental observations were made in China before 1950 (Tao et al., 1997; Cao et al., 2013), most of them were inhomogeneous due to inconsistent observational schedules in different years, relocations of stations, and missed observations. In recent decades, many studies have focused on achieving continuous and consistent SAT series for the estimation of national averages in China during the 20th century by bringing together the sparse and inconsistent pre-1950 data with the regular observations after 1950 using data quality control, series infill, and data adjustment for homogeneity (Zhang and Li, 1982; Tang and Lin, 1992; Lin et al., 1995; Tang and Ren, 2005; Li et al., 2010; Cao et al., 2013).

Since the instrumental observation data over most of China began in the 1950s, it is important to reconstruct the regional temperature changes based on temperature proxy data with high time resolution (e.g., phenological data, tree-ring width chronologies) to extend series to compensate for the deficiency of instrumental observations. However, until now, only one such reconstruction has been available in China (Wang et al., 1998). Utilizing the daily mean, maximum, and minimum temperatures; related descriptions of cold/warm events recorded in historical documents for East, Central, and Southwest China; $\delta^{18} \mathrm{O}$ from the ice core in the north of the Tibetan Plateau; and tree-ring data in Tibet, this work has reconstructed the mean annual temperature series from 1880 to 1996 in ten regions: Northeast, North, East, South, Taiwan, South Central, Southwest, Northwest, Xinjiang, and Tibet. Although these series have become important data to illustrate regional temperature changes in China over the last century (Tang et al., 2009), several flaws remain in the data, e.g., the incoherence of the accuracy in temperature anomaly estimations in the periods 1880-1910, 1911-1950, and 1951-1996, and the limited spatial representation and large uncertainty of the proxy data before 1950. In particu- 
lar, these flaws are mostly related to the limitations of proxy spatial coverage and the weak relationship between regional temperature changes and proxy data for calibration in the reconstruction; for example, the correlation coefficient between the grades of cold/warm events and the temperature was lower than 0.6 , and the temperature reconstruction only captured lower than $35 \%$ temperature variance. Thus, it is imperative to reconstruct a higher-quality data set on regional temperature changes that spans a longer timescale by using more proxy data and developing a new approach for reconstruction. Here, we present a new reconstruction of annual temperature anomalies in South Central China dating back to 1850 using phenological data and natural evidence.

\section{Material and method}

\subsection{Instrumental data}

The instrumental data used in the study are Chinese monthly temperature anomalies starting in January 1951 (with respect to 1971-2000 mean climatology). This gridded data set with a spatial resolution of $0.5^{\circ} \times 0.5^{\circ}$ was developed and updated by the National Climate Center (Xu et al., 2009) and released by the Chinese Meteorological Administration (http://cdc.nmic.cn/home.do). As our aim was to reconstruct the annual temperature anomalies in South Central China, the mean annual temperature anomalies for all grids in the study area (Fig. 1) were calculated for calibration and validation. The study area was divided by Wang et al. (1998) originally according to Chinese climate regionalization and the coherence of temperature changes. The spatial correlations between the annual regional mean temperature series and the temperature for each grid show that $98 \%$ of the grids have a spatial correlation higher than 0.70 , with the minimum value being 0.35 , which also exceeds the $\alpha=0.01$ significant level (Fig. 2). This indicates that the regional mean temperature series represents the temperature variation for each grid in the study area very well. Therefore, the proxy data records at any site within (or near to) the area could be considered as indicators for the whole region.

\subsection{Proxy data}

Three types of proxy data were used in this study to reconstruct temperature changes: phenological data, snowfall day data, and tree-ring width, chronologies. The locations of all proxy data are illustrated in Fig. 1.

\subsubsection{Phenological data}

The phenological data include the spring phenodates of plants derived from historical diaries and modern phenological observations. In the traditions of Chinese society, it was customary for scholars to write personal diaries based on their interests, and most of them contain daily weather

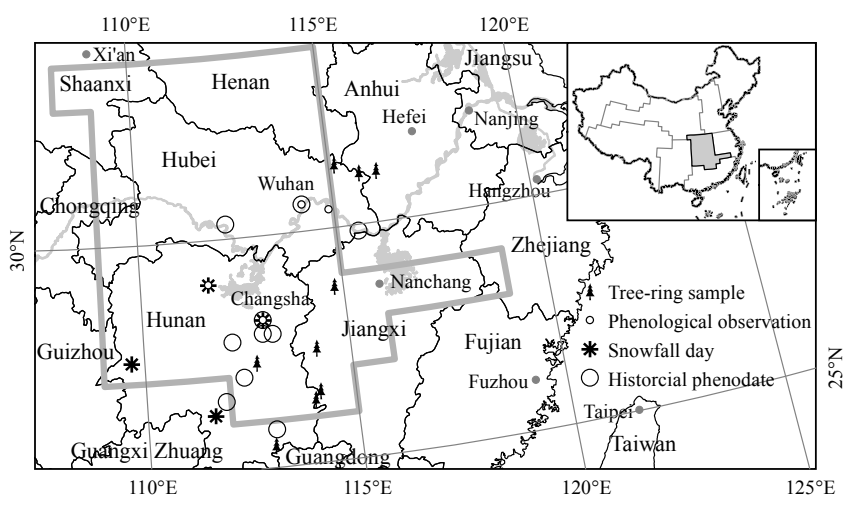

Figure 1. The study area and locations of proxy data used for annual temperature reconstruction in South Central China. Top right: subregions divided by the climate regionalization and the coherences of temperature change (cited from Wang et al., 1998). The gray area indicates South Central China.

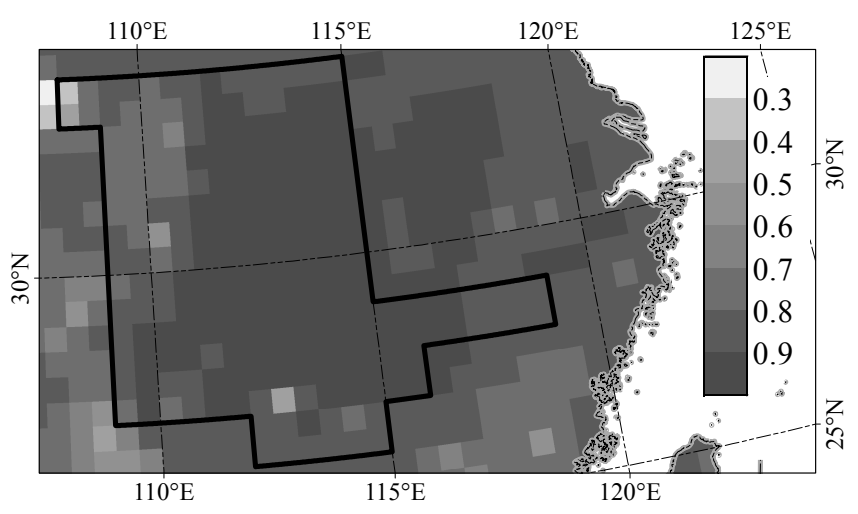

Figure 2. The spatial correlation between annual regional mean temperature series and each grid temperature in the study area.

and related timely phenological phenomena of ornamental plants near their residences. By looking through detailed descriptions from six historical diaries, we extracted information regarding the recording place, species, and spring phenodates (see Supplement Table S1 for details). Moreover, observational data were obtained from the Chinese Phenological Observation Network, which was established in 1963 but which was interrupted during the periods 1968-1972 and 1996-2002 in most places (Ge et al., 2010). The flowering dates of the sakura (Prunus yedoensis) at Wuhan University $\left(31.54^{\circ} \mathrm{N}, 116.36^{\circ} \mathrm{E}\right)$ starting in 1947 (Chen et al., 2008) were also collected. Although the historical phenological data were accurate and objective and could be used as a reliable proxy for temperature reconstruction (Chu, 1973; Aono and Kazui, 2008; Bradley, 2014), they differed from the observational data in the phenological network, which had fixed places, species, and criteria (Chu and Wan, 1980). As there was only one phenodate record per year for most years (see Table S1) within the historical time, we merged the historical and observational data into the regional spring phenodate 
series with homogenized annual anomalies, following the approach used to reconstruct regional spring phenodates series for the past 150 years over the Yangtze River Delta of China (Zheng et al., 2013).

Firstly, we used observational data to calculate the mean phenodate and annual deviation for all phenophases (e.g., swelling of bud, first flowering, full flowering) and all species from each site used in this study. Then, the differences between the historical phenodate and the mean phenodate in the observational period were calculated for each historical phenological record of the given phenophases, species, and sites. Secondly, we calculated the correlation coefficients of spring (March-April) phenodates among different phenophases for all species. The results show that the correlation coefficients of all the spring phenophases used in this study vary from 0.72 to 0.97 , which are all statistically significant and exceed the 0.05 significance level. This indicates that these phenophases have good synchronicity in annual phenological variation.

As there are no interruptions in the series of flowering dates of Prunus yedoensis at Wuhan University since 1947, which is the longest and most continuous of all the available phenological observation data sets, we selected this series as the reference phenodate series for the study area. Then, the phenodate anomalies for each record from the historical and the observation data were calculated with the same reference date (19 March), the mean phenodate of 1951-2000 for first flowering of Prunus yedoensis in Wuhan, by subtracting the difference between the mean phenodate of the given phenophases in a given site and first flowering of Prunus yedoensis in Wuhan within the same observational period based on the phenophases with synchrony of annual phenological variation.

For example, there were many historical phenodate records on the flowering of Prunus persica, e.g., first flowering on 19 March 1892 and 24 March 1893 at Hengyang city. From the observational data, the mean phenodate of first flowering of Prunus persica at Hengyang was 8 March in the period 1964-1989, except for the interrupted years of 1968-1972. From the observations at Wuhan University, the mean phenodate of first flowering of Prunus yedoensis was 20 March in the period 1964-1989 (excluding the years 1968-1972), which is 1 day later than the reference date. Based on the analysis of correlation of the observation data, it is found that the flowerings of Prunus persica and Prunus yedoensis have good synchronicity (correlation coefficient of 0.89 ) in their annual flowering variation. Thus, it is easy to obtain that the first flowerings of Prunus persica were 12 days and 17 days later than the reference date in 1892 and 1893, respectively, at Hengyang. Since we have proved that the proxy data records at any site in the area could be indicators for the whole region (see Sect. 2.1), these delayed (or advanced) days could be regarded as anomalies of the regional spring phenodates.
Finally, the regional spring phenodate series with homogenized annual anomalies was reconstructed by merging the annual anomalies from historical records (or their means if there were several records) and those from the observation series of flowering dates of Prunus yedoensis at Wuhan University. By comparing to the spring phenological index (SPI) series in the subtropical regions of China in the period 1850 2009 reconstructed by Wang et al. (2014), the correlation coefficient between our regional spring phenodate series and the SPI series was found to be 0.61 , which exceeds the 0.001 significance level. This fact confirmed that the approach for regional spring phenodate series reconstruction in our study is reasonable. Moreover, based on both phenological and temperature data from 1951 to 2007, the correlation coefficient between annual regional homogenized spring phenodate anomalies and temperature anomalies is -0.53 , which exceeds the 0.001 significance level.

\subsubsection{Snowfall day data}

The snowfall days were extracted from historical archives (called "Yu-Xue-Fen-Cun") and weather observations from four stations located in Hunan Province. Yu (rainfall)Xue (snowfall)-Fen (Chinese length unit, approximately $0.32 \mathrm{~cm}$ )-Cun (approximately $3.2 \mathrm{~cm}$ ) is a type of memo that was reported to the emperor by governmental officers during the Qing Dynasty from 1644 to 1911 . These memos recorded rain infiltration depth measurements from the dry-wet soil boundary layer to the ground surface taken by digging into the soil with a shovel after rainfall, and the snow depth on the surface after each snowfall event at 273 administrative sites across China. Yu-Xue-Fen-Cun employed a fixed-report format, and the measurements were performed at fixed sites by fixed observers, making it a systematic and homogeneous data set. Moreover, these data are believed to be highly reliable and accurate (Ge et al., 2005). Thus, the snowfall days recorded in Yu-Xue-Fen-Cun are nearly the same as those recorded by modern weather stations, and these data have been used to reconstruct the variation in winter temperature at the middle and lower reaches of the Yangtze River since 1736 (Hao et al., 2012). By combining historical snowfall day records and observational data since 1951, the mean annual snowfall day anomaly series from four stations since 1850 was reconstructed. The correlation coefficient between the snowfall day and annual temperature from 1951 to 2007 is -0.48 , which exceeds the 0.001 significance level.

\subsubsection{Tree-ring width data}

Five tree-ring width chronologies (Table 1) derived from recent publications were used in this study (Duan et al., 2012; Zheng et al., 2012; Cao et al., 2012; Shi et al., 2013; Cai and Liu, 2013). In these chronologies, dating and measurement errors were all checked with the COFECHA computer program, and all chronologies were developed using the AR- 
STAN program. In the chronologies from Duan et al. (2012) and Shi et al. (2013), a cubic smoothing spline with a $50 \%$ frequency response cutoff equal to 80 years was employed to remove tree-age-related growth trends in each tree. In the other three chronologies from Zheng et al. (2012), Cao et al. (2012), and Cai and Liu (2013), the detrending method for removing tree-age trend for each tree-ring width series was the best fitting with a negative exponential curve or a linear trend with a negative slope.

Analysis of the relationship between tree-ring width and climate showed that the growth of trees in the study area was affected not only by the mean or minimum temperatures in certain months (e.g., late winter to mid-summer) and maximum temperatures in summer and early fall but also by the climatic conditions in the previous year. In Table 1 , we present the correlation coefficients to test whether these chronologies include the regional temperature signals. The results show that all chronologies are significantly correlated with annual regional temperature changes, and most of the correlation coefficients between changes in tree-ring width and annual regional temperature of the previous year are also statistically significant. It is worth noting that a negative correlation between tree-ring width and temperature existed in the chronology of Pinus massoniana Lamb. in Macheng County. The reason is that these tree-ring samples were collected from a site with a relatively low altitude $(500-540 \mathrm{~m})$, which caused the June-September temperatures to become the main limiting factor for tree growth due to the advancing of tree dormancy induced by higher water evaporation due to higher maximal temperatures in the daytime. Meanwhile, higher temperatures during the nighttime could also result in increasing respiration. Both of these lead to tree growth being negatively correlated with temperature (Cai and Liu, 2013).

\subsection{Reconstruction and analysis methods}

We applied stepwise regression in Minitab to develop a calibration equation, in which the regional temperature anomaly $(T)$ is the dependent variable and the independent variables are phenodate $(P)$, snowfall days $(S)$, and five tree-ring width chronologies in both the current year and in the following year (i.e., $X_{1}, X_{1}(t+1), \ldots, X_{5}, X_{5}(t+1)$ ). To avoid discrepancies in dimensions and lengths for different series, all proxy data series were standardized by the mean and standard deviation of each series in their common period of 1951-2000. The leave-one-out cross-validation method (Michaelsen, 1987) was then adopted for verification in order to select the optimal equation with the highest predicted $R^{2}$ value for reconstruction. The uncertainty interval for the reconstruction was set as twice (i.e., in the $95 \%$ confidence level) the standard error of prediction. As data for some years were missing in the series of spring phenodate anomalies and snowfall days, and two of the five tree-ring width chronologies did not extend back to 1850 , regression equations (Table 2) were constructed based on the available proxy data.

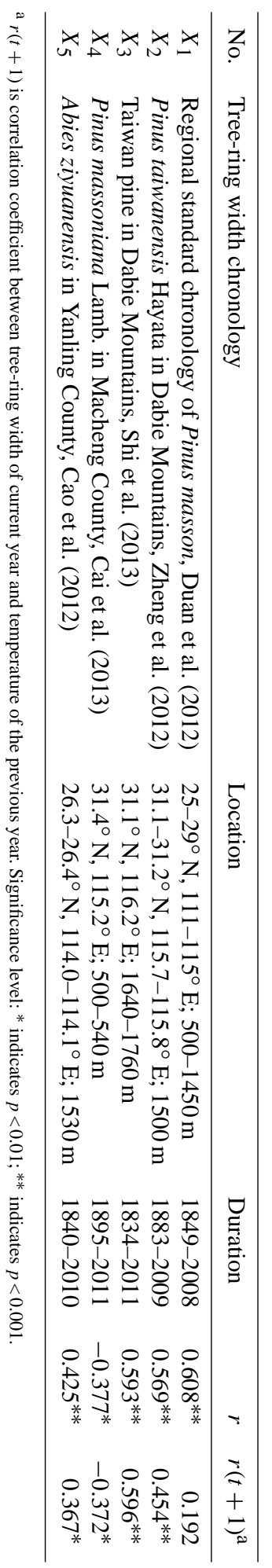

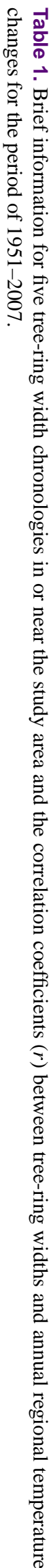




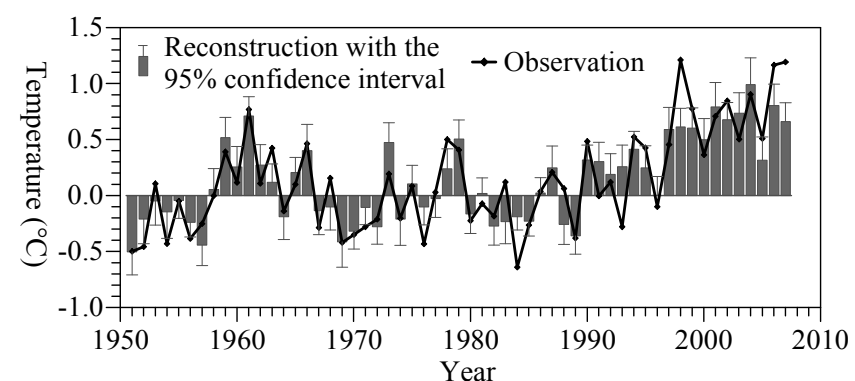

Figure 3. Comparison between the reconstructed and observed annual mean temperatures from 1951 to 2007.

For example, to reconstruct the temperature anomalies for 66 years when all seven proxy data were available, stepwise regression was conducted based on all independent variables to establish the calibration equation (Eq. 1 in Table 2). Stepwise regression was conducted based on only the independent variables $\mathrm{S}, X_{1}, X_{1}(t+1), \ldots, X_{5}, X_{5}(t+1)$ to establish the calibration equation (Eq. 2 in Table 2 ) for temperature anomaly reconstruction when phenological data were unavailable. Table 2 shows that the predicted $R^{2}$ values of all calibration equations exceed $50 \%$, ranging from 56 to $66 \%$. This suggests that all calibration equations are valid for reconstruction.

Finally, the full series was constructed by merging the reconstructions for individual periods. As the reconstructions for specific years were calibrated from different equations with different variances and predicted sums of squares, the magnitudes of the reconstructed temperatures for specific years had to be adjusted using variance matching with the standard deviations of the predictands in common years during the calibration period. For example, the standard deviations of the predictand series in the common years of 19522006 (excluding 1997 and 1998 because of the lack of snowfall data) derived from Eqs. (1) and (2) are $0.35(s 1)$ and $0.42(s 2)$, respectively; thus, the reconstructed temperature anomalies in 1903 and 1904 derived from Eq. (2) should be adjusted by dividing by the value of $s 2 / s 1$. Moreover, the Mann-Kendall test (Wei, 2007) was applied to detect the trend and abrupt change for the reconstructed series of annual temperature anomalies in South Central China from 1850 to 2008.

For comparison, we also conducted a reconstruction for the growing season (March-October) mean temperature with the same method using phenological and tree-ring width data. However, the predicted $R^{2}$ values $(0.41-0.43)$ of all calibration equations for the growing season mean temperature reconstructions were less than those for the annual mean temperature reconstructions.

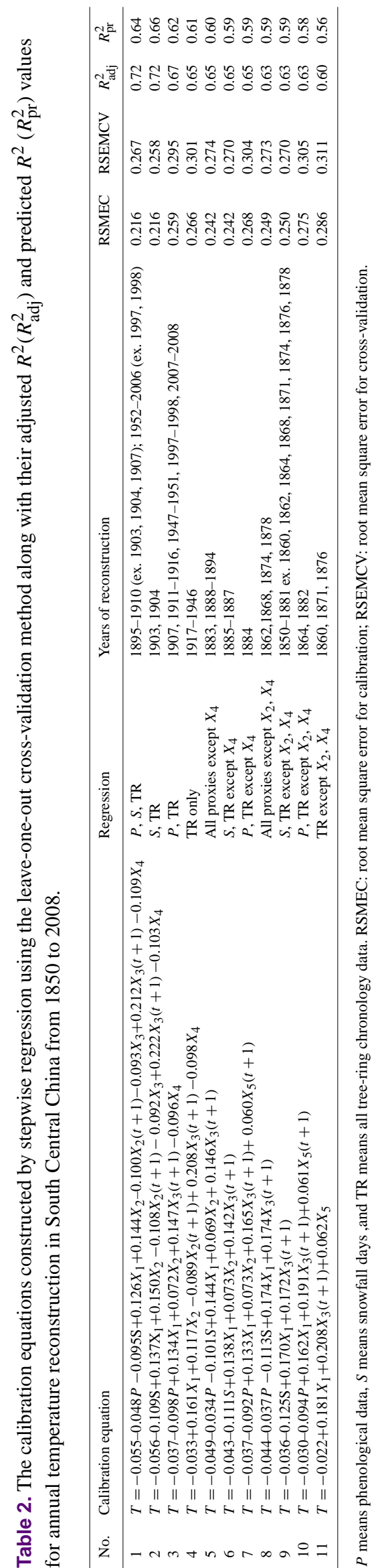

Clim. Past, 11, 1553-1561, 2015 


\section{Results and discussion}

Figure 3 shows a comparison between the reconstructed and observed annual mean temperatures from 1951 to 2007. From Fig. 3, it can be seen that the reconstruction captures the temperature variations quite well at an interannual to decadal timescale, and shows a rapid increase from the mid1980s onward. Figure 4 shows the reconstructed series of annual and growing season temperature anomalies and their $95 \%$ confidence intervals in South Central China from 1850 to 2008 , and a comparison with other series of temperature observations. Figure $4 \mathrm{a}$ indicates that the temperature change in South Central China in the past 150 years was characterized by interannual and interdecadal fluctuations before the 1980 s and warming after the $1990 \mathrm{~s}$; the maximum amplitudes were $1.6^{\circ} \mathrm{C}$ for interannual and $0.8^{\circ} \mathrm{C}$ for interdecadal variations. The warm decades occurred in the $1850 \mathrm{~s}$, 1870s, and 1960s, as well as during the 1920s-1940s; the warmest decades were the 1990s-2000s, which included 9 of the 10 warmest years from 1850 to 2008 . Although the warm interval of the 1920s-1940s persisted for more than 20 years, the level of warmth was notably lower than that in the 1990s-2000s. Cold intervals occurred in the 1860s, 1890s, and 1950s, with slightly colder years occurring in the 1970s and 1980s. The Mann-Kendall test indicated that, except for the notable cooling in the 1860s, the temperature fluctuated without any evident trend from the 1870 s to the 1980s. However, significant warming has occurred since the 1990s, with an abrupt change around 1997, which caused the unprecedented variability in warming.

The results also confirmed that 1893 was the coldest year during the period 1850-2008, which has been found at most sites in China in previous studies (Gong et al., 1987; Hao et al., 2011; Zhang and Liang, 2014), with many descriptions of cold climate conditions recorded in historical documents. For example, after a series of strong cold waves hit China in the winter of 1892 (December 1892 to February 1893), large-scale rain, snow, and freezing weather phenomena occurred in South Central China; severe sea ice occurred in the coastal areas of northern Jiangsu Province (approximately $32-35^{\circ} \mathrm{N}$ ), and the thickness of ice cover on Taihu Lake (approximately $30.9-31.6^{\circ} \mathrm{N}, 119.9-120.6^{\circ} \mathrm{E}$ ) reached more than $1 \mathrm{ft}$ (Gong et al., 1987). More than 10 frozen days were recorded for the Huangpu and Wusong rivers in Shanghai, where the historical documents only occasionally recorded freezing during the winter of the Little Ice Age. Even the Qiantang River froze in January 1893; historical documents indicate that this river has only frozen three times during the past 2000 years (the other two freezes occurred in the winters of 1152 and 1690) (Hao et al., 2011). Moreover, the diary of Zhang Jian reported that Prunus mume was not in full blossom in Suzhou (east of China; $31.1^{\circ} \mathrm{N}, 120.6^{\circ} \mathrm{E}$ ) until 21 March 1893, due to the extreme cold weather in the winter and early spring, which was delayed by 27 days compared to the mean of the period 1977-1996 (Zheng et al., 2013). In the diary of Xiangqi-Lou, the author, Wang Kaiyun, noted, “ On the 7th day in the second lunar month (24 March 1893) in Hengyang, Hunan Province, Prunus persica began to blossom. The phenodate in this spring was the latest one in my all records." This indicated that the delayed spring phenophase in 1893 was far more significant than that which the authors were accustomed to.

By comparing the reconstructions between annual (Fig. 4a) and growing season (Fig. 4b) temperatures, they have very similar decadal variations but have a bit of difference at interannual change. Specifically, the growing season temperature reconstruction does not capture the warm years of 1978 and 1979 shown in the observations. The growing season temperature reconstruction shows that the coldest year within the period 1850-2008 was 1969, rather than 1893 as in the annual temperature reconstruction, which is consistent with the previous results. Moreover, the growing season reconstruction shows a smaller variability before 1870 than after, while the annual reconstruction shows a similar variability throughout the whole series.

Comparison of the reconstructed series with the observed temperature series (Fig. 4c-f) demonstrated that the reconstruction matched well with the observed data in Wuhan since 1906 (Fig. 4c, the longest observation within the study area), especially in the decadal variations and most of the interannual variations. The reconstructed and observed data both demonstrated a warm interval of greater than 20 years during the 1920s-1940s, an evident cold decade around 1950 , and unprecedented warming beginning in the 1990s. The reconstruction here also matched well with the regional mean (Fig. 4d) from the Climatic Research Unit (CRU) gridded temperature data from 1901 in most of the interannual and decadal variations, except for differences in the 1900s, late 1930s, and late 1940s. This might be caused by the spatial interpolation using observed temperatures outside of the study area in the CRU gridded temperature data, because no observations were available before 1906 and very few observations were available from the late 1900s to mid-1920s as well as the late 1930s to late 1940s in this area due to social unrest and war. Although the different multi-decadal variations and trend are shown in our reconstruction and the observed temperature in Shanghai from 1873 (Fig. 4e), the correlation coefficient is 0.43 , which exceeds the 0.001 significance level. In particular, both of our reconstructions show rapid warming since the 1980s; several consecutive cold years around 1970; and a few consecutive warm years around 1914, 1942, and 1960.

Moreover, the temperature change in South Central China (Fig. 4c) was different from that in the Northern Hemisphere (Fig. 4f). The warm interval in the 1920s-1940s indicated by both the reconstructed and the observed data for South Central China was more evident than that found in the Northern Hemisphere. Specifically, the temperature in the Northern Hemisphere in general exhibited an increasing trend with a rate of $0.85^{\circ} \mathrm{C}$ per 100 years from 1880 to 2012 , whereas the 


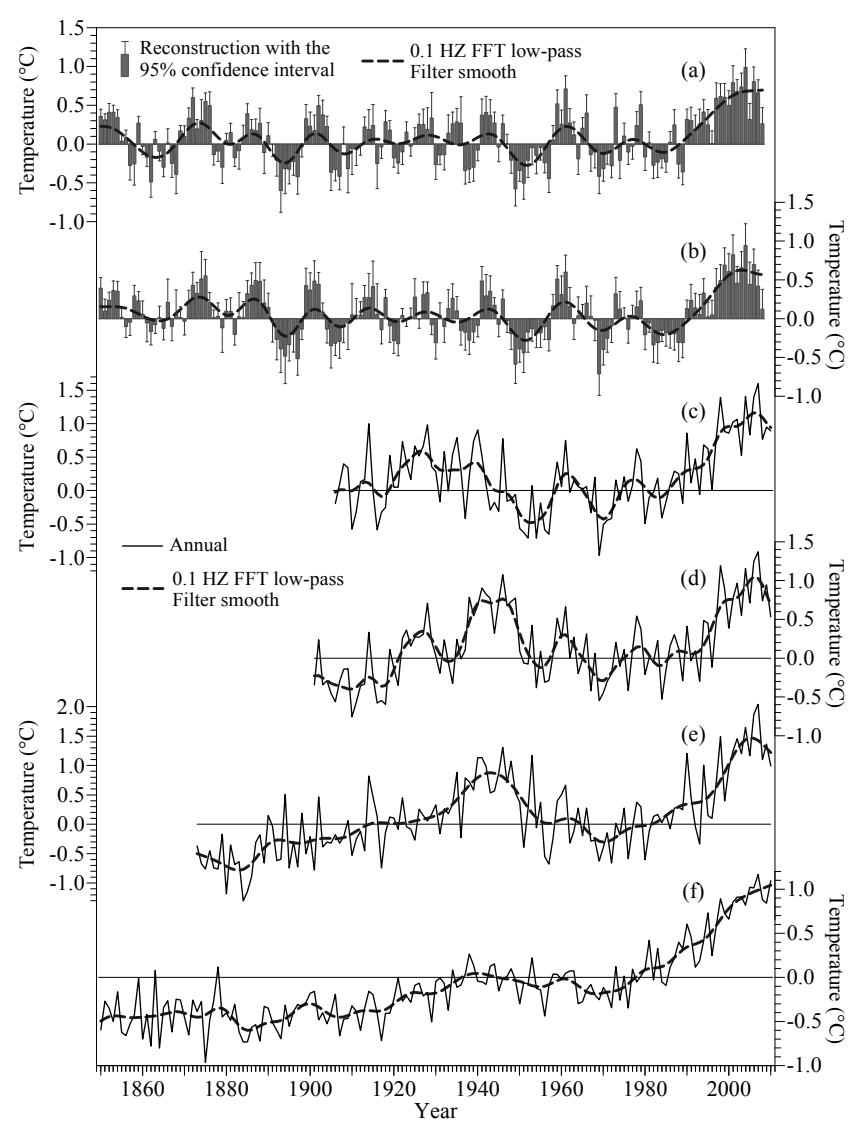

Figure 4. Reconstruction of annual and growing season temperature anomalies (with respect to the mean climatology from 1961 to 1990 , as for other series) with a $95 \%$ confidence interval in South Central China from 1850 to 2008 and comparison with other observations. (a) Annual temperature reconstruction. (b) Temperature reconstruction for growing season. (c) Observed annual temperature anomalies at the Wuhan weather station during 1906-2010 (Cao et al., 2013). (d) Regional mean temperature anomalies from CRU gridded data during 1901-2010. (e) Observed annual temperature anomalies at the Shanghai weather station during 1873-2010 (Cao et al., 2013). (f) Northern Hemisphere land air temperature anomalies during 1850-2010 from CRU (http://www.cru.uea.ac.uk/ cru/data/temperature/CRUTEM4v-nh.dat).

rate of increase in South Central China was only $0.28^{\circ} \mathrm{C}$ per 100 years from 1880 to 2008 . This might be partly attributed to the difference in temperature change between regional and hemisphere scales; the rate of temperature increase in Wuhan was only $0.52^{\circ} \mathrm{C}$ per 100 years from 1906 to 2010 , which is $50 \%$ lower than the rate in the Northern Hemisphere in general $\left(1.06^{\circ} \mathrm{C}\right.$ per 100 years $)$.

However, uncertainties are still presented in our reconstructions. These uncertainties might arise from the following factors: the phenological and snowfall data were missing in some years, and the temperature anomalies in these years (a total of 33 years) could only be reconstructed by using tree-ring width data. As pointed out by many stud- ies (see the review paper of Yang et al., 2011), the tree-ring width data hardly capture the low-frequency trend signal due to growth detrending. Meanwhile, the multi-collinearity and transfer function's instability with time may be involved in the calibration method of multiple regression because the tree-ring width chronologies used are highly correlated with each other. In addition, the reconstructions from all of the proxy data only explain part of the temperature variabilities. Thus, our reconstructions may underestimate the increasing trend of the temperature change. These shortcomings will be improved in future studies when more proxy data become available.

Compared with using one single type of proxy data (e.g., tree-ring width or historical cold/warm event records) to reconstruct regional temperature changes, our reconstruction has the advantage of utilizing multiple types of proxy data (i.e., phenological, snowfall day, and tree-ring width data), which can capture more information and reduce the uncertainties in the results. For example, a comparison of our reconstructions with previous seasonal temperature reconstructions using single tree-ring width (Duan et al., 2012; Cao et al., 2012; Shi et al., 2013; Cai and Liu, 2013) or snowfall day records (Hao et al., 2012) shows that our annual temperature series can capture higher variances (greater than $56 \%$; see Table 2) in temperature observations. The reconstructions derived from a combination of phenological data, snowfall days, and tree-ring width chronologies on annual temperature can also capture higher temperature variances than those only using phenological data and tree-ring width chronologies for growing season temperatures. The main reason for this might be that the phenological changes are highly sensitive to late winter and spring temperatures. Tree-ring width data from highlands in this area are sensitive to springsummer minimum and mean temperatures (i.e., they are positively correlated) (Duan et al., 2012; Zheng et al., 2012; Shi et al., 2013); however, the data from lower lands are negatively correlated with late summer and early fall maximum temperatures (Cai and Liu, 2013). The snowfall days in this area are strongly correlated with winter temperatures (Hao et al., 2012). This combination of different proxy data types could therefore capture more complete temperature change signals from different seasons and different sites than those from a single proxy data type, which will benefit optimal model selection for calibration.

In addition, compared to the annual temperature reconstructions in this area from 1880 (Wang et al., 1998), our reconstruction is extended to 1850 , and the accuracy is improved, with a maximum uncertainty interval of only $0.35^{\circ} \mathrm{C}$ (see Fig. 4a) at the $95 \%$ confidence level. Furthermore, the reconstruction of Wang et al. (1998) showed that the warmest period since 1880 was the 1920 s-1940s, when the temperature was much higher than that of the 1990s, with no increasing trend since 1880 . Our reconstruction also reveals the increasing temperature trend from 1880 , particularly the more evident trend from the late 1940s and the warmest decades 
in the 1990s and 2000s, which match well with 20th century global warming.

\section{Conclusion}

We have presented new annual temperature reconstructions with a maximum uncertainty interval of $0.35^{\circ} \mathrm{C}$ at the $95 \%$ confidence level in South Central China from 1850 to 2008 by synthesizing phenological, snowfall day, and tree-ring width data. The results suggest that the temperature changes in South Central China over the past 150 years were characterized by interannual and interdecadal fluctuations before the $1980 \mathrm{~s}$, with a maximal amplitude of $1.6^{\circ} \mathrm{C}$ for interannual and $0.8^{\circ} \mathrm{C}$ for interdecadal variations. However, rapid warming has occurred since the 1990s, with an abrupt change around 1997, leading to unprecedented variability in warming. A cold interval dominated the 1860 s, 1890s, and 1950s, with slightly cold intervals around 1970 and in the 1980s. The coldest year overall was very likely 1893 . Warm decades occurred around 1850,1870, and 1960, along with the 1920s-1940s. The warmest decades were the 1990s2000s, which included 9 of the 10 warmest years from 1850 to 2008. However, our reconstructions may underestimate the increasing trend in temperature; this should be improved in future studies when more proxy data become available.

\section{The Supplement related to this article is available online at doi:10.5194/cp-11-1553-2015-supplement.}

Acknowledgements. This study was supported by the Strategic Priority Research Program of the Chinese Academy of Sciences (no. XDA05090104, no. KJZD-EW-TZ-G10), the National Natural Science Foundation of China Key Program (no. 41430528), and the Basic Research Project of the Ministry of Science and Technology (no. 2011FY120300).

Edited by: J. Luterbacher

\section{References}

Aono, Y. and Kazui, K.: Phenological data series of cherry tree flowering in Kyoto, Japan, and its application to reconstruction of springtime temperatures since the 9th century, Int. J. Climatol., 28, 905-914, 2008.

Bradley, R. S.: Paleoclimatology: Reconstructing Climates of the Quaternary, 3rd Edn., Elsevier/Academic Press, San Diego, 675 pp., 2014.

Cai, Q.-F. and Liu, Y.: The June-September maximum mean temperature reconstruction from Masson pine (Pinus massoniana Lamb.) tree rings in Macheng, southeast China since 1879 AD, Chinese Sci. Bull., 58, 169-177, 2013 (in Chinese).
Cao, L.-J., Zhao, P., Yan, Z.-W., Jones P.-D., Zhu, Y.-N., Yu, Y., and Tang, G.-L.: Instrumental temperature series in eastern and central China back to the nineteenth century, J. Geophys. Res.Atmos., 118, 8197-8207, doi:10.1002/jgrd.50615, 2013.

Cao, S.-J., Cao, F.-X., and Xiang, W.-H.: Tree-ring-based reconstruction of temperature variations from May to July since 1840 in Yanling county of Hunan province, China, Journal of Central South University of Forestry \& Technology, 32, 10-14, 2012 (in Chinese).

Chen, Z.-H., Xiao, M., and Chen, X.: Change in flowering dates of Japanese cherry blossoms ( $P$. yedoensis Mats) in Wuhan University campus and its relationship with variability of winter temperature, Acta Ecologica Sinica, 28, 5209-5217, 2008 (in Chinese).

Chu, K.-C.: A preliminary study on the climate changes since the last 5000 years in China, Scientia Sinica, 16, 226-256, 1973.

Chu, K.-C. and Wan, M.-W.: Phenology, Science Press, Beijing, 1980 (in Chinese).

Duan, J.-P., Zhang, Q.-B., Lv, L.-X., and Zhang, C.: Regional-scale winter-spring temperature variability and chilling damage dynamics over the past two centuries in southeastern China, Clim. Dynam., 39, 919-928, 2012.

Ge, Q.-S., Zheng, J.-Y., Hao, Z.-X., Zhang, P.-Y., and Wang, W.C.: Reconstruction of historical climate in China: high-resolution precipitation data from Qing dynasty archives, B. Am. Meteorol. Soc., 86, 671-679, 2005.

Ge, Q.-S., Dai, J.-H., and Zheng, J.-Y.: The Progress of Phenology Studies and Challenges to Modern Phenology Research in China, Bulletin of Chinese Academy of Sciences, 25, 310-316, 2010 (in Chinese).

Gong, G.-F., Zhang, P.-Y., and Zhang, J.-R.: Chilly winter of 18921893 and its effect, Collected Papers of Geography, 18, 129-138, 1987 (in Chinese).

Hansen, J., Ruedy, R., Sato, M., and Lo, K.: Global surface temperature change, Rev. Geophys., 48, RG4004, doi:10.1029/2010RG000345, 2010.

Hao, Z.-X., Zheng, J.-Y., Ge, Q.-S., and Ding, L.-L.: Variation of extreme cold winter events in Southern China during the past 400 years, Acta Geographic Sinica, 66, 1479-1485, 2011 (in Chinese).

Hao, Z.-X., Zheng, J.-Y., Ge, Q.-S., and Wang, W.-C.: Winter temperature variations over the middle and lower reaches of the Yangtze River since 1736 AD, Clim. Past, 8, 1023-1030, doi:10.5194/cp-8-1023-2012, 2012.

Jones, P. D., New, M., Parker, D. E., Martin, S., and Rigor, L. G.: Surface air temperature and its changes over the past 150 years, Geophys. Rev., 37, 173-199, doi:10.1029/1999RG900002, 1999.

Jones, P. D., Lister, D. H., Osborn, T. J., Harpham, C., Salmon, M., and Morice, C. P.: Hemispheric and large-scale landsurface air temperature variations: An extensive revision and an update to 2010, J. Geophys. Res.-Atmos., 117, D05127, doi:10.1029/2011JD017139, 2012.

Lawrimore, J.-H., Menne, M. J., Gleason, B. E., Williams, C. N., Wuertz, D. B., Vose, R. S., and Rennie, J.: An overview of the global historical climatology network monthly mean temperature data set, version 3, J. Geophys. Res., 116, D19121, doi:10.1029/2011JD016187, 2011.

Li, Q.-X., Dong, W.-J., Li, W., Gao, X.-R., Jones, P., Kennedy, J., and Parker, D.: Assessment of the uncertainties in temperature 
change in China during the last century, Chinese Sci. Bull., 55, 1974-1982, doi:10.1007/s11434-010-3209-1, 2010.

Lin, X.-C., Yu, S.-Q., and Tang, G.-L.: Series of Average Air Temperature over China for the Last 100-Year Period, Scientic Atmospherica Sinica, 19, 525-534, 1995 (in Chinese).

Michaelsen, J.: Cross-validation in statistical climate forecast models, J. Clim. Appl. Meteorol., 26, 1589-1600, 1987.

Rohde, R., Muller, R., Jacobsen, R., Perlmutter, S., Rosenfeld, A., Wurtele, J., Wickham, C., and Mosher, S.: Berkeley Earth Temperature Averaging Process, Geoinfor Geostat: An Overview, 12, 1-13, doi:10.4172/2327-4581.1000103, 2013.

Shi, J.-F., Edward, R.-C., Li, J.-B., and Lu, H.-Y.: Unprecedented January-July warming recorded in a 178-year tree-ring width chronology in the Dabie Mountains, southeastern China, Palaeogeogr. Palaeocl., 381-382, 92-97, doi:10.1016/j.palaeo.2013.04.018, 2013.

Tang, G.-L. and Lin, X.-C.: Average air temperature series and its variations in China, Meteorological Monthly, 18, 3-6, 1992 (in Chinese).

Tang, G.-L. and Ren, G.-Y.: Reanalysis of surface air temperature change of the last 100 years over China, Climatic and Environmental Research, 10, 791-798, 2005 (in Chinese).

Tang, G.-L., Ding, Y.-H., Wang, S.-W., Ren, G.-Y., Liu, H.-B., and Zhang, L.: Comparative Analysis of the Time Series of Surface Air Temperature over China for the Last 100 Years, Advances in Climate Change Research, 5, 71-78, 2009 (in Chinese).

Tao, S.-Y., Fu, C.-B., Zeng, Z.-M., Zhang, Q.-Y., and Kaiser, D.: Two long-term instrumental climatic data bases of the People's Republic of China, Carbon Dioxide Information Analysis Center, Oak Ridge National Laboratory Oak Ridge, Tennessee, 1997.
Wang, H.-J., Dai, J.-H., Zheng, J.-Y., and Ge, Q.-S.: Temperature sensitivity of plant phenology in temperate and subtropical regions of China from 1850 to 2009, Int. J. Climatol., 35, 913-922, 2014.

Wang, S.-W., Ye, J.-L., Gong, D.-Y., Zhu, J.-H., and Yao, T.-D.: Construction of mean annual temperature series for the last one hundred years in China, Quarterly Journal of Applied Meteorology, 9, 392-401, 1998 (in Chinese).

Wei, F.-Y.: Technology of Statistical Diagnosis and Prediction of Modern Climate, 2nd Edn., Meteorological Press, Beijing, 2007.

Xu, Y., Gao, X.-J., Shen, Y., Xu, C.-H., Shi, Y., and Giorgi, F.: A daily temperature dataset over China and its application in validating a RCM simulation, Adv. Atmos. Sci., 26, 763-772, 2009.

Yang, B., Sonechkin, D. M., Datsenko, N. M., Ivashchenko, N. N., Liu, J.-J., and Qin, C.: Eigen analysis of tree-ring records: Part 1, a limited representativeness of regional curve, Theoretical Appl. Climatol., 106, 489-497, 2011.

Zhang, D.-E. and Liang, Y.-Y.: A study of the severest winter of 1892/1893 over China as an extreme climatic event in history, Quaternary Sciences, 34, 1176-1185, 2014 (in Chinese).

Zhang, X.-G. and Li, X.-Q.: Some characteristics of temperature variation in China in the present century, Acta Meteorol. Sin., 40, 198-208, 1982 (in Chinese).

Zheng, J.-Y., Zhong, S.-Y., Ge, Q.-S., Hao, Z.-X., Zhang, X.Z., and Ma, X.: Changes of spring phenodates for the past 150 years over Yangtze River Delta, J. Geogr. Sci., 23, 31-44, doi:10.1007/s11442-013-0991-0, 2013.

Zheng, Y.-H., Zhang, Y., Shao, X.-M., Yin, Z.-Y., and Zhang, J.: Climate significance of tree ring width of Huangshan Pine and Chinese Pine in the Dabie Mountains, Progress in Geography, 31, 72-77, 2012 (in Chinese). 